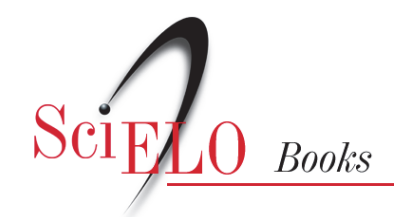

\title{
Apresentação
}

Teoria quântica: história e cultura

Olival Freire Jr.

Osvaldo Pessoa Jr.

Joan Lisa Bromberg

FREIRE JR, O., PESSOA JR, O., and BROMBERG, JL., orgs. Teoria Quântica: estudos históricos e implicações culturais [online]. Campina Grande: EDUEPB; São Paulo: Livraria da Física, 2011. 456

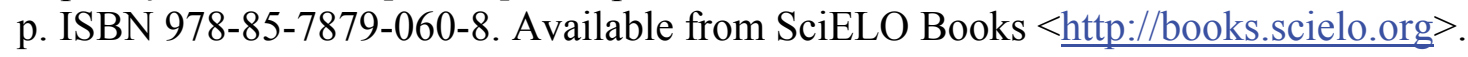

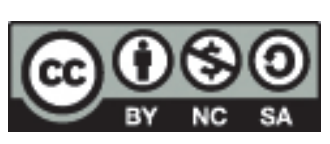

All the contents of this work, except where otherwise noted, is licensed under a Creative Commons Attribution-Non Commercial-ShareAlike 3.0 Unported.

Todo o conteúdo deste trabalho, exceto quando houver ressalva, é publicado sob a licença Creative Commons Atribuição Uso Não Comercial - Partilha nos Mesmos Termos 3.0 Não adaptada.

Todo el contenido de esta obra, excepto donde se indique lo contrario, está bajo licencia de la licencia Creative Commons Reconocimento-NoComercial-CompartirIgual 3.0 Unported. 


\section{Apresentação \\ Teoria Quântica: História e Cultura}

A Teoria Quântica, desenvolvida no primeiro quartel do século XX, é a mais bem sucedida teoria física hoje disponível. A confiança que os físicos nela depositam é de tal ordem que os desenvolvimentos teóricos ulteriores a tomam como um quadro referencial básico para pensar a Física. Desde as primeiras aplicações tecnológicas, com a invenção do transistor e do laser, até as atuais promessas no campo da informação quântica, o seu manancial de aplicações parece inesgotável. Em que pese esse sucesso científico e tecnológico, persiste entre os cientistas incertezas sobre a interpretação dos próprios fundamentos dessa teoria científica. As incertezas derivam do fato de que ela desafia as nossas intuições não só de senso comum mas mesmo aquelas enraizadas no desenvolvimento da Física nos últimos séculos. Não é de estranhar, portanto, que a segunda metade do século XX tenha presenciado um renascimento tanto da controvérsia, quanto das investigações sobre os fundamentos dessa teoria. Essa controvérsia não tem sido estéril. Hoje, compreendemos melhor a Teoria Quântica como consequência dessa controvérsia e da pesquisa que ela engendrou. A propriedade física do emaranhamento entre sistemas quânticos espacialmente separados, evidenciada no Teorema de Bell, hoje largamente aceita como um genuíno efeito quântico e colocada na base das pesquisas sobre informação quântica, tem suas raízes associadas a críticos dos fundamentos dessa própria teoria, como Albert Einstein, David Bohm, John Bell, John Clauser e Abner Shimony. No início deste ano, o prestigiado Prêmio Wolf de Física foi atribuído a John Clauser, Alain Aspect e Anton Zeilinger pelos seus experimentos com emaranhamento de fótons. O prêmio reconheceu pelo menos um físico que sempre foi um crítico dos fundamentos da Teoria Quântica, no caso John Clauser.

A controvérsia sobre os fundamentos da Teoria Quântica tem fascinado a muitos, bem além do círculo dos próprios físicos. A capa deste livro reflete essa fascinação, por estar inspirada em escultura de Albert Einstein e Niels Bohr, os principais protagonistas da controvérsia sobre os quanta, em um parque em Moscou. Imagens dos dois gigantes da Física tornaram-se ícones da Física do século XX. A controvérsia é comparada, muitas vezes, àquela que opôs Newton 
a Leibniz. Enquanto a controvérsia que está na origem da ciência moderna, no século XVII, é parte da história, a controvérsia sobre os quanta é contemporânea e estamos todos nela imersos, como partícipes.

Em 1974, o historiador Max Jammer finalizou seu The philosophy of quantum mechanics afirmando que a história dessa controvérsia é uma "história sem fim"; e acrescentou, lembrando o ensaísta francês Joseph Joubert, que "é melhor debater uma questão sem resolvê-la do que resolver uma questão sem debatê-la." Mais de 30 anos depois, as afirmativas de Jammer guardam plena atualidade.

A presente obra - Teoria quântica: estudos históricos e implicações culturais - é uma coletânea de trabalhos que exploram aspectos da história dessa teoria científica, desde sua criação aos desenvolvimentos ulteriores, incluindo a controvérsia sobre os seus fundamentos e sobre suas implicações filosóficas e culturais. Discute também problemas relacionados à pesquisa sobre o ensino e a difusão cultural dessa teoria, bem como os usos, e abusos, que aí podem aparecer.

Tanto o aparecimento deste livro, quanto o evento científico que esteve em sua origem (workshop com o mesmo nome, realizado em Campina Grande, Paraíba, entre 14 e 17 de dezembro de 2008), acontecem no Brasil em um momento oportuno. Há cerca de 15 anos vem crescendo no Brasil o número de pesquisadores dedicados a trabalhos históricos e/ou filosóficos sobre a Teoria Quântica, muitos deles autores deste trabalho, sem que se houvesse realizado até o momento um evento científico de maior envergadura integralmente dedicado ao tema. Além disso, o workshop e o livro ocorrem em um momento no qual a pesquisa sobre a história da Teoria Quântica ganha novo impulso, seja com o Projeto de História da Física Quântica, promovido pelo Instituto Max Planck de História da Ciência (Alemanha), seja com a realização de conferências internacionais sobre $o$ assunto, em especial a HQ1 (Berlim, 2007); a sessão Interpreting Quantum Mechanics - a Century of Debate, na HSS (Washington, 2007); a HQ2 (Utrecht, 2008); e a HQ3 (Berlim, 2010), todas com a participação de pesquisadores brasileiros.

O desenvolvimento da pesquisa sobre história da Teoria Quântica no Brasil também se beneficia da sua relação com a história da Física brasileira. Se é verdade que a pesquisa em Física moderna no Brasil só recebeu um momentum intelectual e institucional a partir da criação da USP, em 1934, já passada a fase áurea da criação da Teoria Quântica, também é verdade que aspectos relevantes da pesquisa e da controvérsia sobre os fundamentos dessa teoria tiveram como cenário a Física brasileira. Quando no início da década de 1950, o físico David Bohm passou três anos na Universidade de São Paulo, fugindo da perseguição do macarthismo, muito da pesquisa e dos debates sobre a interpretação causal da Teoria Quântica proposta por ele ocorreu naquela universidade. O trabalho conjunto com Jayme Tiomno e os embates com Mário Schenberg, físicos brasileiros, são parte dessa história. Mario Bunge, Jean-Pierre Vigier e Ralph Schiller 
vieram ao Brasil para trabalhar com Bohm, enquanto Léon Rosenfeld veio para estabelecer o contraponto entre a interpretação causal e a visão da complementaridade patrocinada pelo físico dinamarquês Niels Bohr. Ainda na década de 1960 foi a vez de Klaus Tausk, professor da USP, envolver-se em acirrada controvérsia com físicos italianos e com Rosenfeld sobre o problema da medição na Teoria Quântica. Pouco depois, o físico brasileiro José Leite Lopes, exilado em Estrasburgo, na França, junto com o físico francês Michel Paty, promoviam evento, que gerou o livro Quantum mechanics - a half century later, que contribuiu para criar um espaço favorável à pesquisa sobre os fundamentos da Teoria Quântica. Recentemente, os desenvolvimentos teóricos sobre o efeito descoerência e o experimento tipo "gato de Schrödinger", que testou pela primeira vez esse efeito, contam entre seus protagonistas com os físicos brasileiros Amir Caldeira e Luiz Davidovich.

Os capítulos deste livro estão organizados em quatro partes. A primeira, intitulada História da teoria quântica - desenvolvimentos e fundamentos, reúne artigos com uma abordagem eminentemente histórica sobre aspectos da pesquisa em Teoria Quântica na segunda metade do século XX. A segunda parte, Implicações filosóficas da teoria quântica, está integrada por textos essencialmente filosóficos, versando sobre a interpretação da Teoria Quântica. As Implicações culturais e educacionais da teoria quântica, terceira parte, referem-se a fenômenos, como o "misticismo quântico," a presença da quântica no teatro e o ensino dessa teoria física. Por fim, a última parte, Construção da teoria quântica: história e tendências de pesquisa, está composta por trabalhos históricos que exploram o período da construção da Teoria no início do século XX, bem como trabalhos que mesclam abordagens históricas com possibilidades atuais de desenvolvimento da pesquisa em seus fundamentos.

O livro compreende 21 capítulos e 28 autores, divididos entre brasileiros e estrangeiros, em proporções aproximadamente iguais. Reúne desde pesquisadores-sênior a estudantes de pós-graduação. Os trabalhos aqui reunidos foram apresentados em versões preliminares, no workshop que dá origem ao livro. As versões preliminares foram submetidas a um processo de arbitragem e seleção, conduzido pelos organizadores do volume, de modo que esses textos representam um esforço coletivo de discussão e elaboração que teve início naquele workshop e que se prolongou por quase um ano e meio.

Tanto o workshop que lhe deu origem, quanto o próprio livro ora publicado, foram possíveis graças ao apoio do Programa de Doutorado Interinstitucional (DINTER) em Ensino, Filosofia e História das Ciências, oferecido pela Universidade Federal da Bahia (UFBA) e Universidade Estadual de Feira de Santana (UEFS), em parceria com a Universidade Estadual da Paraíba (UEPB). A iniciativa não teria sido possível, entretanto, sem um leque de apoios, sendo o 
mais expressivo dentre eles o da UEPB, por meio de sua Reitoria e Pró-Reitoria de Pós-Graduação e Pesquisa. De fato, o apoio institucional dessa Universidade e o encorajamento recebido da sua Pró-Reitora, Profa. Dra. Marcionila Fernandes, foram essenciais para o sucesso do evento. Além da UEPB, o workshop e o livro contaram com o apoio do IQuanta (Campina Grande); do Departamento de Física da Universidade Federal de Campina Grande (UFCG); da Capes (PROCAD NF UFBA-UFSC-UFRGS); da FAPESB, do CNPq e do Instituto Max Planck de História da Ciência (Berlim). Agradecemos a Christelle Rigal a foto que serviu de base para a capa. Esta imagem já havia antes inspirado a capa do livro Quantum dialogue de Mara Beller.

Olival Freire Jr. Osvaldo Pessoa Jr. Joan Lisa Bromberg 